\title{
Criança de jornal: representações de infância e juventude em Brasil e em Portugal
}

\author{
JULIANA DORETTO \\ Universidade Nova de Lisboa - jdoretto@uol.com.br \\ Doutoranda em Ciências da Comunicação pela Universidade \\ Nova de Lisboa, na área de Estudo dos Media e do Jornalismo. \\ Mestre em Comunicação pelo Programa de Pós-Graduação \\ em Ciências da Comunicação da Universidade de São Paulo (2010). \\ Graduada em Comunicação Social - Jornalismo, também \\ pela Universidade de São Paulo (2002).
}

\begin{abstract}
Resumo
O artigo investiga as formas de representação de infância e juventude que se destacam no noticiário de três jornais diários do Brasil e de Portugal. Analisamos sete edições de cada um dos seguintes periódicos: os brasileiros Folha de S. Paulo e O Estado de S. Paulo e o português Público. A pesquisa revela que os diários apresentam a criança e o jovem como objeto de ações, ou seja, ausente das esferas de decisão e sem direito a opinião. Além disso, ganham destaque tanto a representação dos garotos e das garotas como uma população ameaçada pelos males modernos quanto aquela que os mostra como consumidores autônomos.
\end{abstract}

Palavras-chave

Jornais diários, representações, crianças e jovens

\begin{abstract}
This paper investigates the forms of representation of children and young people that stand out in three daily newspapers in Brazil and Portugal. We analyze seven editions of each of the following newspapers: the Brazilians Folha de S. Paulo and $O$ Estado de S. Paulo and the Portuguese Público. The research reveals that the publications show children and youth as an object of actions, i.e. they are absent from decision-makers arenas and they did not express their opinion. In addition, the representation of boys and girls as a population threatened by modern ills gains prominence, as well their image as autonomous consumers.
\end{abstract}

\section{Keywords}

Newspapers, representations, children and youth

Artigo recebido em 10/09/2012

Aprovado em 02/10/2012 


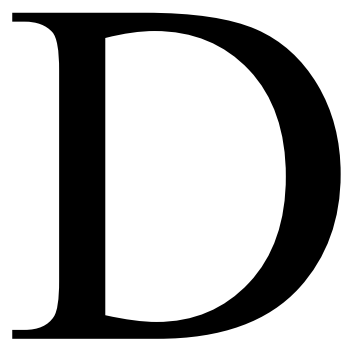

e um lado, a criança e o jovem ameaçados pelos males modernos: as doenças advindas dos maus hábitos; a perseguição dos colegas; a educação de má qualidade. De outro, garotos e garotas na esfera familiar estruturada: aquela em que, ao mesmo tempo em que têm de ser protegidos, eles ganham autonomia para consumir. Em ambos, a criança e o jovem como objeto de ações: ausentes das esferas de decisão e sem direito a opinião. Nessas formas de representação é que se assenta boa parte de uma amostra do noticiário sobre crianças e jovens de três jornais diários, do Brasil e de Portugal.

Para chegar a esses dados, investigamos sete edições dos periódicos brasileiros Folha de S. Paulo, segundo colocado na circulação no país, com cerca de 297 mil exemplares/dia, segundo dados de 2011 do IVC (Instituto Verificador de Circulação; o primeiro é um jornal popular, o Super Noticia, de Minas Gerais, sem abrangência nacional), e $O$ Estado de $S$. Paulo (que, apesar de ser apenas o quinto mais vendido no país, com 236 mil exemplares/dia, é o principal concorrente da Folha); e do português Público, um dos diários de referência em Portugal, ao lado de O Diário de Notícias (MARÔPO, 2009), e o quarto em circulação no país, com aproximadamente 29 mil exemplares/dia, de acordo com a Associação Portuguesa para o Controlo de Tiragem e Circulação. Foram selecionados textos publicados entre os dias 29 de abril (domingo) e 5 de maio (sábado) e que traziam como mote quaisquer assuntos relacionados a crianças e jovens (até 18 anosi ), incluindo os que foram publicados em suplementos e revistas. Para que análise mais consistente da narrativa jornalística pudesse ser feita, os textos de dimensão muito reduzida (notas) não foram incorporados ao corpus da pesquisa. A investigação também não selecionou as fotografias que acompanhavam as reportagens.

$\mathrm{O}$ número de notícias encontradas vem ao encontro do que mostra nossa revisão de literatura. Apesar de até aos anos 1990 predominar, no Brasil e em Portugal, o pouco interesse pela cobertura dos temas relacionados à vida da criança e do jovem (MARÔPO, 2009; PONTE, 2005; ANDI, 2005), o fim da década 1090 e o decorrer dos anos 2000 mostraram uma mudança de espectro. Em 2005, retomando a pesquisa anterior feita de modo oblíquo por três décadas (1970-2000) e estendendo-a de dois para quatro veículos portugueses, Ponte e Afonso expuseram que houve aumento no número de textos que abordavam a temática. O mesmo crescimento foi observado nos jornais brasileiros: “em 1996, [...] nos 50 principais jornais do País, sobre as questões 
concernentes ao público infanto-juvenil, monitorou-se um total de 10.700 inserções. Em 2002, os números impressionavam: haviam sido contabilizadas 93.581 matérias" (ANDI, 2005, p. 4).

Em nossa amostra, foram encontradas, ao todo, 37 peças: 11 textos em sete dias no Estado de S. Paulo (não houve publicação relacionada a crianças e jovens apenas em 4 de maio); 17 na Folha (novamente, sem notícias somente no dia 4); e 9 no Público (sem texto selecionado no dia 30). É importante ressaltar, porém, que, em cada um dos suplementos infantis dos dois jornais brasileiros, houve apenas uma reportagem sobre o universo específico das crianças e dos jovens, o que denota o pouco caráter noticioso dessas publicações, em detrimento do aspecto de entretenimento, conforme identificado em trabalho anterior sobre esses cadernos (DORETTO, 2010). No entanto, assim como a pesquisa de Ponte e Afonso apontou que o crescimento do número de peças "não correspondeu a um alargamento da agenda das notícias na perspectiva das políticas de infância, nem dos olhares sobre a globalização e os seus impactos" (2005, p. 43), nota-se que, em nossa amostra, houve concentração em alguns temas e formas de apresentar a criança na narrativa jornalística.

Para chegarmos a essa conclusão, lançamos mão de uma sistematização feita por Ponte e Afonso (2009, p. 43), em pesquisa sobre a imprensa portuguesa, que condensa a representação das crianças e dos jovens nas notícias em quatro grandes categorias temáticas: a criança aluno ("genérica e abstrata [...], afectada pelo confronto entre agentes sociais"; "objecto de discussão como investimento, do Estado e das famílias", ou, resumidamente, "o aluno seu filho"); a criança ameaçada (que aparece em casos de "violência sexual a doenças, acidentes, guerras, catástrofes naturais [...]"; em outras palavras, "podia ser o seu filho"); a criança maltratada ("associada a famílias disfuncionais e a ambientes de pobreza social", ou "o filho dos outros"); a criança investida, objeto de atenção da família e que está relacionada a "novas tendências, comportamentos, consumos e estilos de vida", ou "os nossos filhos").

Assim, a título de exemplo e para elucidar a classificação feita, entendemos que a criança aluno é aquela que aparece em textos como os intitulados "Jovens brasileiros conciliam bem ciência e religião" (Estado, 29 de abril) — que mostra a relação dos alunos que creem em Deus com a teoria de Darwin - e "Director do Porto julgado por agredir aluno" (Público, 5 de maio) - que relata um caso de maus tratos a criança na escola. No entanto, em uma reportagem que explora o ambiente acadêmico, 
mas o extrapola - como "Alunos portugueses são dos que mais se sentem stressados com a escola" (Público, 2 de maio), que fala das pressões escolares, mas traz também dados sobre a saúde dos jovens, como obesidade e uso de álcool —, a representação da criança encontrada pode ser outra que a da criança aluno: no exemplo citado, seria a da criança ameaçada por práticas pouco saudáveis e vícios. Da mesma maneira, no caso das reportagens que abordam o bullying, publicadas na Folha de S. Paulo em 29 de abril ("Justiça já condena jovens envolvidos em bullying", e textos correlatos), a representação que aí aparece é a da criança sofrendo com uma perseguição que, apesar de estar ligada à escola, não se limita a ela.

Essa criança ameaçada também surge na notícia sobre a falha de um tratamento para diabete do tipo 2 em crianças (Estado, $1^{\circ}$ de maio) — uma doença que, quando não controlada, pode provocar "perda de visão e a amputação de membros", segundo palavras do jornal. Na mesma categoria se enquadram casos como o do texto "Bebê morre e família acusa roubo de órgãos" (Estado, 2 de maio), em que o corpo do menino poderia ter sido violado, ou na reportagem sobre desaparecimentos de crianças em Portugal, no Público de $1^{\mathrm{o}}$ de maio, que marca o medo do "vizinho do lado" (PONTE, 2005, p. 274), ou da insegurança da "rua" - que surge com o aumento da criminalidade e da violência na contemporaneidade.

Por fim, a criança maltratada está ligada àqueles casos em que os meninos e as meninas vivem em cenários de pobreza, como uma favela carioca ("Só no passinho", sobre um grupo de dança, na Folha de 29 de abril) ou a Grécia atual ("As crianças gregas? Também estão a pagar pela crise", no Público do mesmo dia), imersa em grande crise financeira. Enquanto a criança investida é aquela que é público para os suplementos infantis dos jornais brasileiros (escritos para os filhos dos leitores dos diários) ou aquela cujos pais recebem aconselhamentos para conseguir um melhor estilo de vida - como o texto "A família toda mudou hábitos" (Folha, 29 de abril) — ou são apresentados a informações sobre o comportamento dos filhos e de si mesmos ("Namoro e sexo em Portugal: a ruptura deu-se entre avós e adolescentes", de 4 de maio). O Gráfico 1 sintetiza os dados encontrados: 


\section{Gráfico 1}

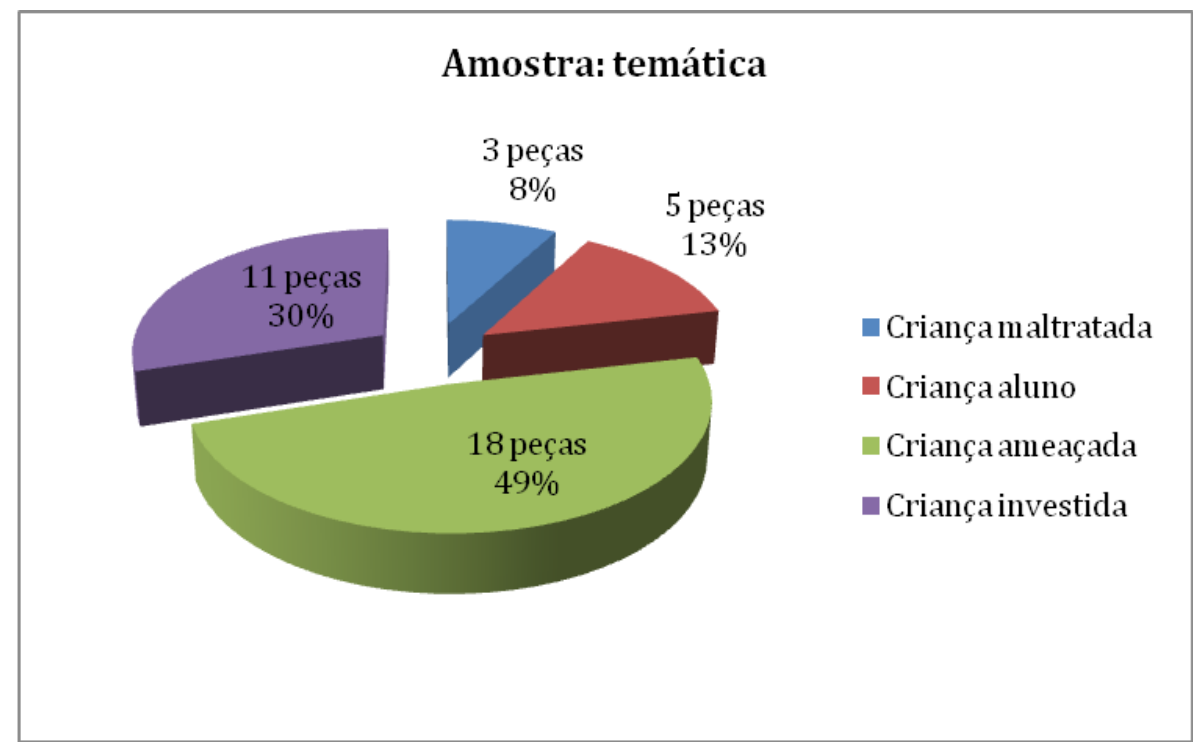

\section{Temática: representações em destaque}

Os números do Gráfico 1, acima, mostram que há predomínio, em toda a seleção de peças, da criança ameaçada, presente em quase metade dos textos (18 das 37 notícias). Essa representação, por sua vez, aparece em reportagens sobre saúde (9 peças ou cerca de 50\% dos casos), sequestro (4 textos; 22\%), bullying (4 peças; 22\%) e sexualidade (1 texto, 6\%). Veja:

\section{Gráfico 2}

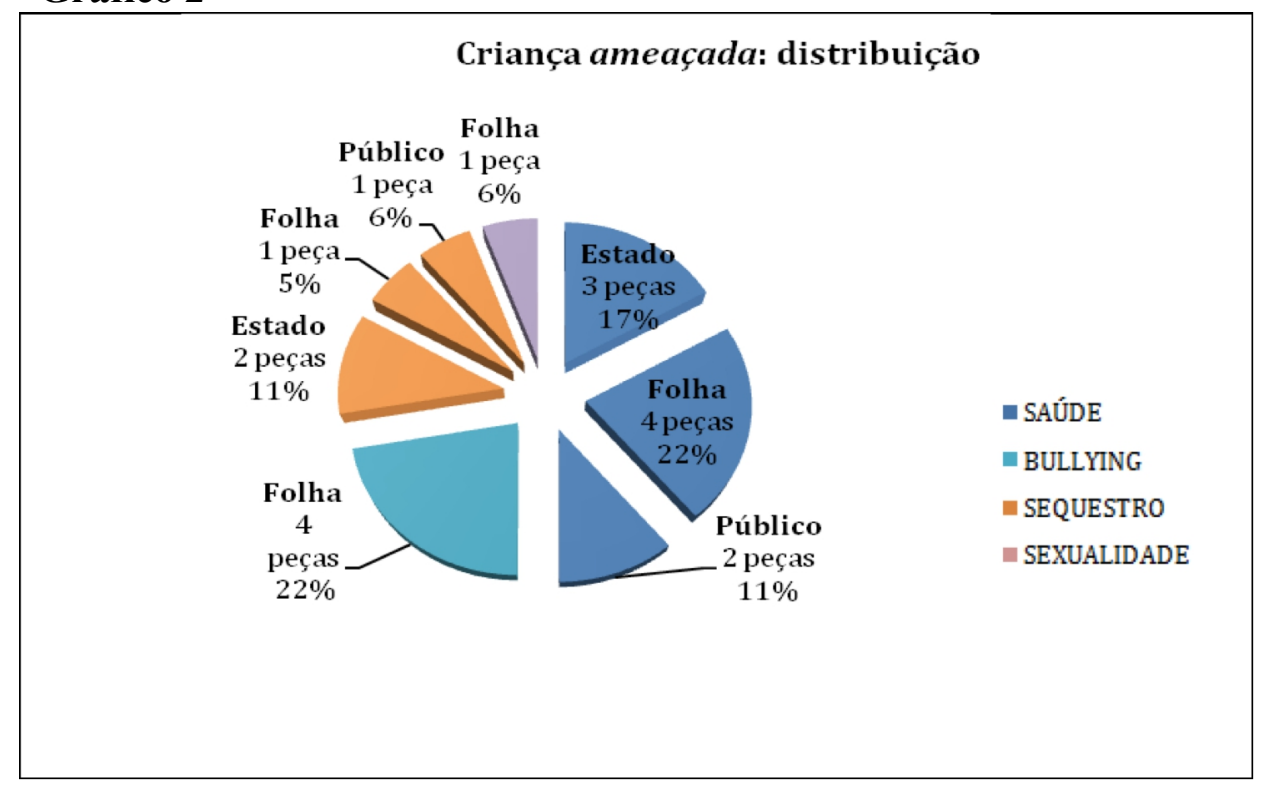


Os dados encontrados indicam grande preocupação dos periódicos estudados com doenças que atingem a infância e a juventude (não uma criança/jovem genérico, mas a que "podia ser seu filho", como Ponte define) em decorrência dos maus hábitos vigentes e das pressões sentidas na sociedade contemporânea, como a diabete e a obesidade $^{\mathrm{ii}}$. Um caso bastante curioso dessa representação está no texto do periódico Público "Venda de remédios contra défice de atenção em alta" (4 de maio), que não discute a necessidade ou não de as crianças tomarem o remédio, mas fala de possíveis problemas que a falta da medicação pode causar, o que poderia ser entendido como uma espécie de naturalização da doença (apenas na última frase o texto diz que "a administração destes medicamentos a crianças tem gerado polêmica em muitos países"):

o neuropediatra Nuno Lobo Antunes, responsável pelo Centro de Apoio ao Desenvolvimento Infantil (Cadin), em Cascais, considerou que a ruptura de stock é "maçadora" e pode causar "alguns problemas", mas refuta que este possa ser descrito como um "momento dramático" para crianças com défice de atenção $[\ldots]$

[...] o pediatra Miguel Palha, que dirige a clínica Diferenças, em Lisboa, tinha denunciado que a falta do Rubifen estava a empurrar as crianças que habitualmente tomam este medicamente para "o insucesso escolar e até a reprovação".

Essa abordagem da saúde dos "nossos filhos" traduz a marca do jornalismo "pós-moderno" identificado por Ponte (2005) no noticiário português do fim da década de 1990, orientado para os interesses individuais dos leitores, em detrimentos de grandes questões sociais, de interesse público: no caso dos pais, essas reportagens surgem como auxílio na criação de seus filhos em tempo de globalização, livre economia, enfraquecimento do Estado e, em contrapartida, maior responsabilização individual das famílias. Retomando Gill Valentine (2004), Ponte (2006) diz que "o enfraquecimento de laços de classe e o declínio na confiança nas autoridades vão a par da explosão de informação disponível, com as pessoas hoje a disporem de uma bateria crescente de escolhas e alternativas", numa sociedade com um número cada vez maior de "riscos" a serem enfrentados (LIVINGSTONE, 2007), de modo solitário. Nesse contexto, os media podem representar para os pais importantes aliados, que os munem de informação e os alertam para a falta de medicamentos ou para os riscos da má alimentação, por exemplo. Nessa linha, outro destaque são os textos sobre punições a crianças e jovens que praticam bullying publicados na Folha de 29 de abril, já citados, em que fica claro que o mote da reportagem é o fato de que "cresce envolvimento de alunos de classe média alta" (no subtítulo) — classe para a qual o jornal também se destina. 
Estudos em Jornalismo e Mídia - Vol. 9 № 2 - Julho a Dezembro de 2012

Ainda dentro dessa categoria, a da criança ameaçada, os textos sobre sequestros — que se repetiram nos três jornais — remetiam a casos famosos nos dois países. No Brasil, trata-se da história de Sean Goldman, que foi morar nos EUA com o pai americano depois da morte da mãe brasileira. Ela havia levado o menino ao Brasil sem o consentimento do pai. Houve um texto no Estado que abordou o sequestro de uma menina argentina (5 de maio), mas, nessa notícia, também houve citação ao episódio Sean. Em Portugal, reportagem trazia o número de crianças e adolescentes desaparecidos desde o caso "Maddie", menina inglesa que desapareceu no Algarve e ainda não foi encontrada. Mais uma vez, temos aqui o jornal alertando para o problema "da rua", para a violência da vida cotidiana (com instituições fragilizadas e, no mesmo compasso, riscos crescentes), que pode apanhar uma família a qualquer momento, sugerindo "a leitura da imponderabilidade, do perigo e da ameaça que espreita e que pode atingir qualquer um" (PONTE; AFONSO, 2009, p. 34) - ainda que sequestros de criança continuem sendo situações excepcionais. A repetição das notícias sobre casos como esses mostra que se trata de uma cobertura que está "sob os holofotes" (PONTE; AFONSO, 2009, p. 42): que tem de ser acompanhada passo a passo pelo jornal, quase num tom folhetinesco, sob pena de que, se não o fizer, o concorrente o fará e atrairá os leitores interessados (TRAQUINA, 2005). A repetição, por outro lado, pode também fazer aumentar no leitorado a sensação de insegurança na vida moderna da qual tratam as notícias, alimentando o medo e o sentimento de ameaça constante, num ciclo vicioso. Por fim, a Folha ainda traz uma notícia sobre a exposição do trabalho de uma fotógrafa americana que faz imagens de crianças nuas, o que nos remete à pedofilia, outro tema bastante recorrente quando se trata dos riscos a que as crianças estão sujeitas em nossa sociedade (sobretudo na arena cibernética).

A criança investida, centrada nas "nossas crianças", é outra vertente desse jornalismo "pós-moderno", voltado para os interesses individuais do leitor, em prejuízo do hard news e dos temas nacionais. Trata-se, no entanto, de uma perspectiva de consumo e comportamento, e não de medos e incertezas. Desse modo, lembramo-nos do conceito de "revistização" cunhado pelo jornalista e professor brasileiro Alberto Dines (1986, p. 70), quando os jornais brasileiros passaram por grandes reformas gráficas e de linguagem — tornando-se mais leves no design e um tanto mais informais no texto para concorrer com a recente chegada da televisão ao país, na década de 60 . Em parte das notícias em que aparece essa criança investida, parece estarmos diante de uma etapa mais avançada desse processo de "revistização", em que textos com debates e dicas 
sobre estilos de vida, fortemente associados aos magazines, tomam conta das páginas dos cadernos diários dos grandes jornais - no nosso caso, ressalta-se a presença nas editorias de "cidades", "saúde e ciência" (ou "Vida", no Estado) e "nacional" (ou "Portugal", no Público) —, para além dos suplementos, em que esse perfil de jornalismo também é bastante presente.

Como exemplo do exposto anteriormente, percebe-se que, na distribuição das peças sobre a criança investida, aparece novamente o predomínio da vertente "saúde", mas com enfoque diferente do que encontrado na representação da criança ameaçada: são dicas para os pais combaterem o excesso de peso nos filhos, em reportagens que assumem que as famílias já sabem do risco da obesidade ("Boquinhas fechadas" e "A família toda mudou hábitos", de 29 de abril, na Folha: o subtítulo do primeiro diz que "fazer os filhos que estão acima do peso emagrecer impõe desafios aos pais"); ou uma pesquisa sobre a chupeta, no dia 30 de abril (na Folha), que diz: "colocada de escanteio pelos pediatras, a chupeta voltou à cena com novo papel. [...] pode auxiliar na amamentação" - e traz o depoimento de um pediatra que não recomenda a chupeta em nenhuma ocasião e o de uma mãe cujo bebê usa o objeto. Ambos os textos estão em cadernos diários.

Outra pauta presente nessa categoria é o consumo, com texto sobre festa de debutantes no Estado - pelo viés dos gastos exorbitantes (29 de abril, no caderno de "Cidades") — e outros dois na Folha. Em um deles, na seção diária de cultura, reportagem anuncia o lançamento de um novo canal infantil na TV paga e diz (aos pais) o conteúdo da programação. No outro, no suplemento infantil, as crianças falam sobre o que acharam de um livro ( 5 de maio), mas, nesse caso, a notícia deixa claro que a obra está à venda e dá inclusive seu preço, o que reforça o caráter de consumo do texto, em detrimento ao simples estímulo à leitura. São exemplos de produtos e bens culturais formatados para crianças e jovens e cuja compra pode ser decidida por eles, e não apenas por seus pais. Nota-se, ainda, que a criança investida apareceu pouco no periódico português: em apenas um texto, sobre a sexualidade nas gerações - o que pode denotar que a "revistização" de Dines estaria mais presente nos jornais brasileiros, mas, para confirmar esse indício, seriam necessárias novas pesquisas. 
Gráfico 3

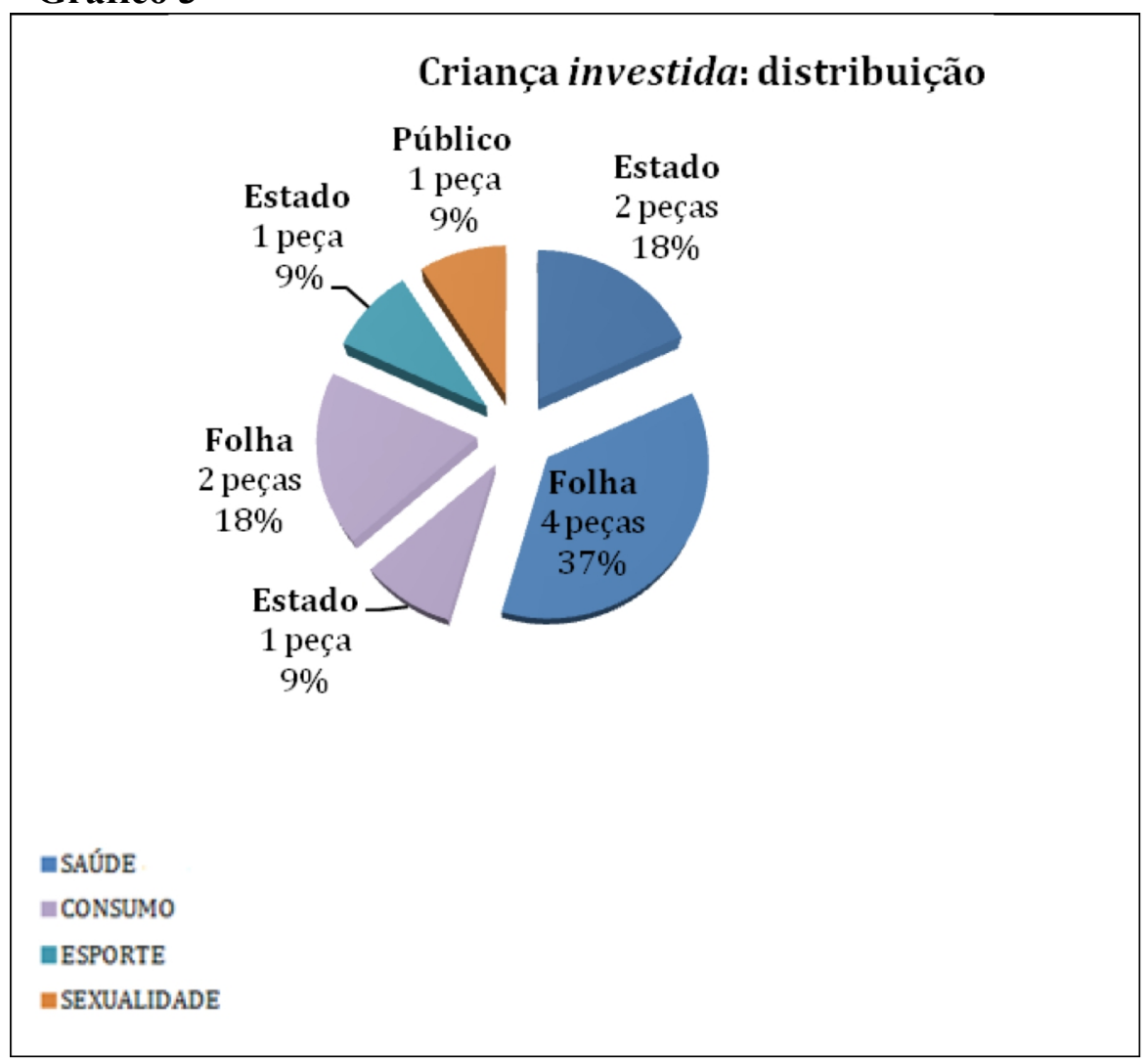

\section{Temática: destaques em cada jornal}

No caso dos periódicos brasileiros, analisando cada diário separadamente, nota-se que tanto o Estado quanto a Folha refletem os dados encontrados na amostra geral: o primeiro traz porcentagens parecidas com as da seleção total, com $46 \%$ de presença da criança ameaçada (contra 49\% na amostra inteira) e 36\% no caso da criança investida (30\%, na análise geral). A Folha dá um destaque ainda maior à criança ameaçada (59\%), e a investida aparece com números parecidos aos do Estado $(35 \%)$.

A criança maltratada, como aquela marcada pela pobreza e pela desestruturação familiar, aparece em uma peça em cada jornal, e essa pouca presença pode ser explicada pela tendência descrita acima de buscar o interesse pessoal dos leitores. A maltratada não é a "nossa criança" e, assim, não faz parte das maiores preocupações dos que leem os jornais (que têm melhor poder aquisitivo, inclusive a ponto de poder comprar o periódico). No Estado, entretanto, esse viés dos interesses pessoais está presente, já que a criança maltratada surge como aquela que pode ameaçar a segurança das famílias, no texto “Jovens já podem ter visita íntima na 
Fundação Casa" (30 de abril) — a notícia traz, entre os pontos negativos da medida, a preocupação de que ela possa suavizar um período que tem de ser entendido como punição. Assim, nesse caso, não se trata da criança ameaçada, mas da "que ameaça". O texto da Folha, por outro lado, mostra uma iniciativa que auxilia as crianças da periferia: uma nova dança que surgiu nas favelas cariocas e que tem fortalecido a autoestima em garotos que a praticam (Folha, 29 de abril). Veja dados nos gráficos abaixo:
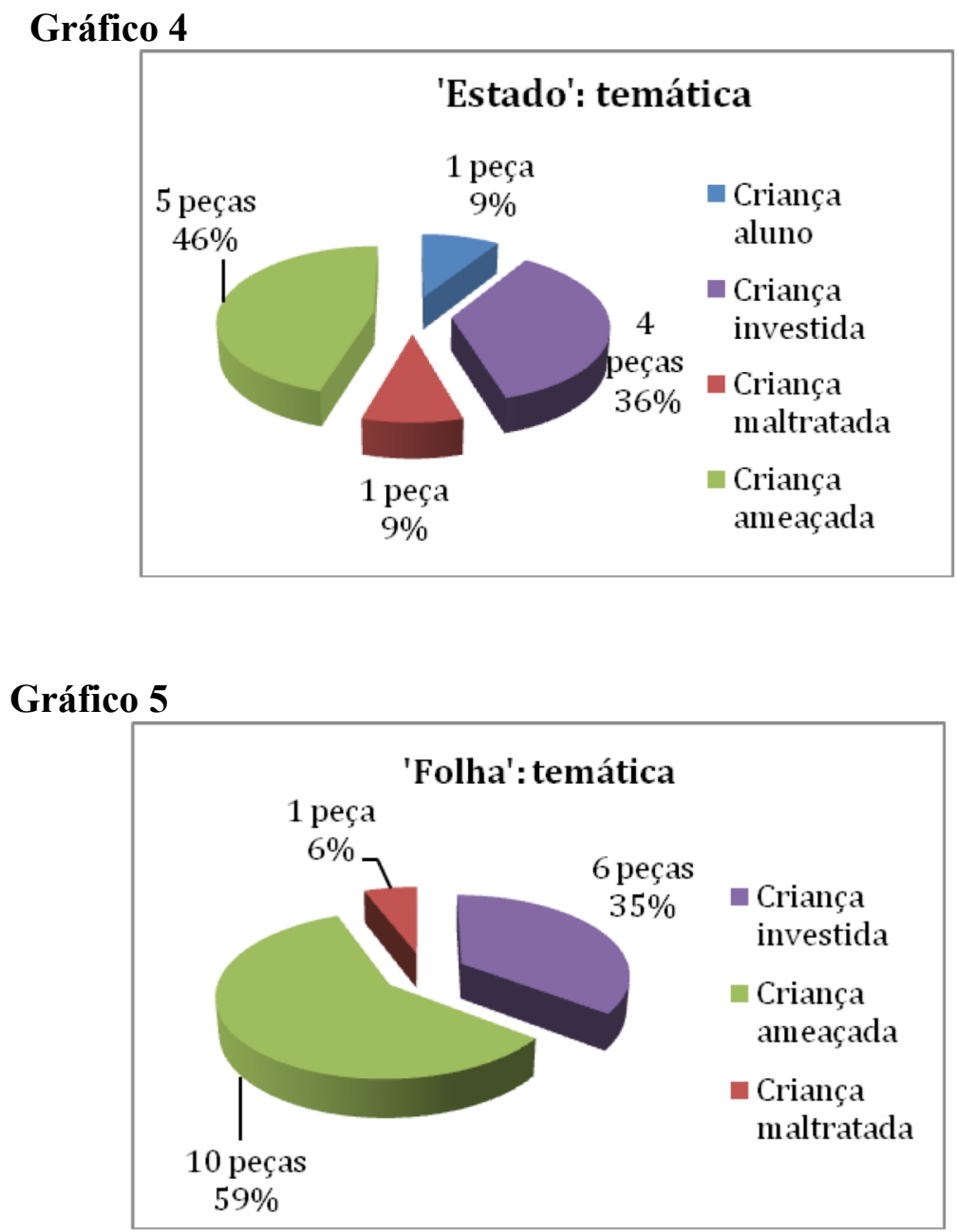

No Público, para além do pouco destaque à criança investida, conforme citado acima, a criança aluno predomina nas peças (em um texto a mais que a ameaçada), sob o ponto de vista do aprendizado e do comportamento das crianças nas escolas. Isso que parece mostrar a maior importância que o periódico dá à temática da educação em relação aos jornais brasileiros — destaca-se a ausência dessa categoria na Folha —, mas aqui também surge a perspectiva do jornalismo "pós-moderno" que procura identificação com o leitor, tendo em vista que os textos não trazem problemas de 
abrangência nacional, de caráter mais estruturante, mas casos locais, como "Escola de Portimão pôs crianças do $1^{\mathrm{o}}$ ciclo a vigiar os intervalos" e "Director do Porto julgado por agredir aluno". A criança maltratada, como nos diários do Brasil, surgiu em um único texto, ligado à crise financeira no continente europeu. Dados estão no Gráfico 6:

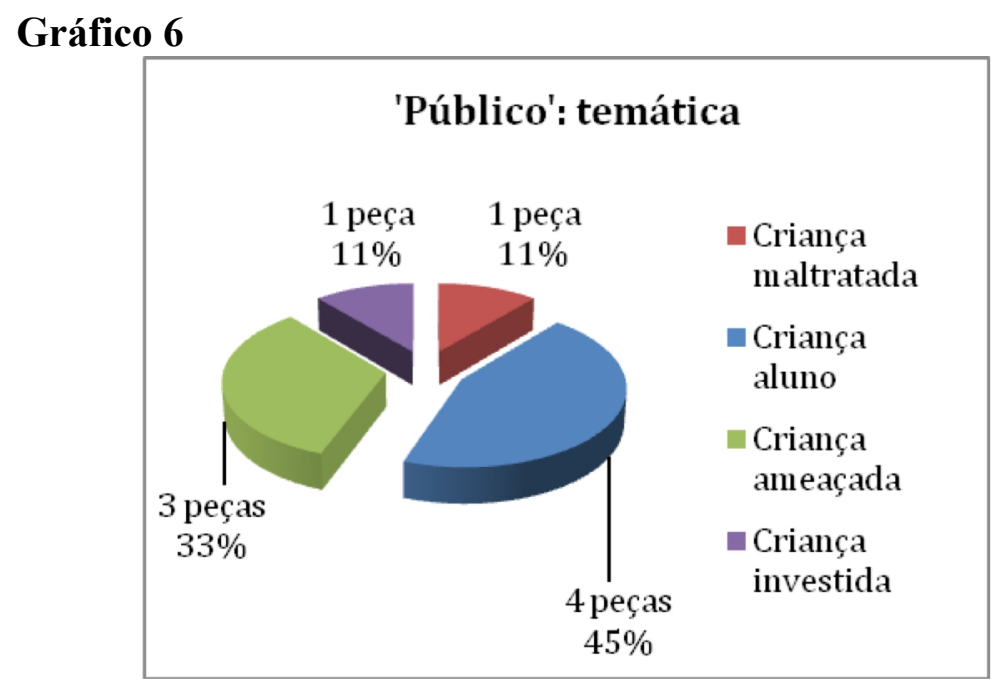

\section{Vozes}

Na continuação da abordagem de Educação no Público, uma das notícias que falam sobre o cotidiano escolar ("O voluntariado chegou às explicações do $1^{\circ}$ ciclo ao ensino secundário", 5 de maio) é um dos poucos exemplos na amostra recolhida em que as vozes das crianças e dos jovens aparecem. No texto, três crianças contam como a ajuda dos voluntários as tem ajudado no desempenho acadêmico: Alexandre, 9 anos, Rita, 8, e Eduarda, 12, dividem o protagonismo no texto com os adultos que as ensinam. Infelizmente, nos oitos textos em que seria possível ouvir garotos e garotas (excetua-se, no caso, a notícia sobre crianças que estão desaparecidas), apenas esse entrevistou crianças (12,5\% das reportagens). Nos jornais brasileiros, novamente a voz da criança e do jovem esteve ausente: no Estado, somente dois, em oito notícias possíveis (25\%); e, na Folha, quatro, entre 12 reportagens (ou 33\%). No Estado, o exemplo que mais se ressalta é o texto "Goleirinho, goleirão", do suplemento infantil "Estadinho" (5 de maio), que ouviu quatro crianças, além de jogadores profissionais: o protagonismo infantil novamente aparece compartilhado. O mesmo acontece na outra notícia, em que mães e debutantes falam sobre as festas, em texto já referido, e, na Folha, na pauta sobre a dança nas favelas cariocas, que ouviu adolescentes e jovens dançarinos e adultos coordenadores de movimentos sociais. 
Por fim, na Folha, a reportagem que traz o selo do antigo caderno juvenil do jornal ("Folhateen"), transformado em seção, com depoimentos de adolescentes que fumam (30 de abril), e a entrevista de uma menina de 14 anos contando sobre o bullying que sofreu, com o título "Tinha medo de apanhar na frente de todo mundo" (20 de abril, t. B5), são textos em que a principal "personagem" das notícias, ou o agente da ação narrada, são as crianças e os jovens.

As peças jornalísticas citadas acima são exemplos que respeitam os direitos dos garotos e das garotos de expressarem suas ideias, de negociarem a construção dos significados de suas próprias histórias na sociedade, de participarem ativamente da construção de sua trajetória de vida, apossando-se dela, e não apenas submetendo-se a outras vozes que a querem comandar - direitos que, inclusive, já estão estabelecidos em um instrumento legal internacional, ratificado pelo Brasil e por Portugal: a Convenção sobre os Direitos da Criança das Nações Unidas (1989).

Nos demais textos, entretanto, ou na maioria do corpus desta pesquisa $(75 \%$ das reportagens em que seria possível ouvir meninos e meninas), ainda que as notícias se voltem para assuntos relacionados às crianças e aos jovens, seus discursos não aparecem: eles são representados como objetos de ações (pesquisas sobre saúde, medidas de cunho educativo) ou tornam-se sujeitos genéricos em notícias que trazem índices gerais de obesidade ou de estresse escolar em faixas etárias específicas. Não há a criança que relata seus problemas com o peso ou a que conta sobre as pressões que sente na escola. São ouvidos apenas pais, educadores e outros profissionais especialistas. Ainda que se leia no Estado a história da garota argentina sequestrada (5 de maio) ou, no Público, a do menino que sofreu agressão do diretor (5 de maio), os relatos dessas crianças não aparecem. Mesmo que a veiculação do nome da criança em situações como essa não aconteça, a fim de protegê-laiii, o seu discurso, mesmo anônimo, poderia estar ali.

Assim, e encaminhando-nos para o encerramento deste trabalho, acreditamos que esses achados vêm a corroborar a conclusão de Marôpo (2009, p. 298-299) em sua tese de doutorado - e, ao mesmo tempo, a necessidade de mudança —, quando ela diz: os pontos de vista de crianças e jovens sobre as questões que lhes dizem respeito são frequentemente silenciados em representações noticiosas que os ignoram como sujeitos de interesse político e social. Nesta perspectiva, é reforçada uma identidade infantil como "objecto de protecção" ou como "projecto de pessoa" em detrimento de uma construção identitária com base em atributos como o protagonismo social, a participação cívica ou o exercício de direitos-liberdades. 


\section{Referências}

ANDI. Imprensa, infância e desenvolvimento humano. Brasília: Andi, 2005. Disponível em: $<$ http://www.andi.org.br/_pdfs/relatorio_7anos_site.pdf>. Acesso em 4 de maio de 2012.

DINES, Alberto. O papel do jornal. São Paulo: Summus: 1986.

DORETTO, Juliana. Pequeno leitor de papel: jornalismo infantil na "Folhinha" e no "Estadinho". Dissertação (mestrado) - Universidade de São Paulo, 2010.

MARÔPO, Lidia S. B. A mediação na construção de uma identidade de direitos da infância: representações jornalísticas de crianças e adolescentes em Portugal e no Brasil. Tese (doutorado) Universidade Nova de Lisboa, 2009.

LIVINGSTONE, Sonia. "From family television to bedroom culture: young people's media at home”. In: E. DEVEREUX (Ed.). Media studies: key issues and debates. London: Sage, 2007.

PONTE, Cristina. Crianças em notícia. Lisboa: ICS/Imprensa de Ciências Sociais, 2005.

PONTE, Cristina. “Crianças em risco. $O$ espaço latino-americano na imprensa portuguesa”. Anais do XXIX Congresso Brasileiro de Ciências da Comunicação. Brasília, 6 a 9 de setembro de 2006.

PONTE, Cristina; AFONSO, Bruna. "Crianças e jovens em notícia: análise da cobertura jornalística em 2005”. In PONTE, C. (Ed.). Crianças e jovens em notícia. Lisboa: Livros Horizonte, 2009.

TRAQUINA, Nelson. Teorias do Jornalismo: v. 2. Florianópolis: Insular, 2005. 


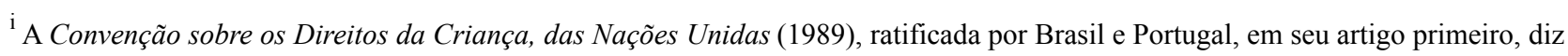
que: "considera-se como criança todo ser humano com menos de dezoito anos de idade, a não ser que, em conformidade com a lei aplicável à criança, a maioridade seja alcançada antes".

${ }^{\text {ii }} \mathrm{O}$ excesso de peso, aliás, foi um tema abordado pelos três jornais (ao lado de sequestro) — mas ele não aparece como ameaça (ou seja, sem vínculo a aconselhamentos) no Estado; com essa temática, está em um texto na Folha (em 30 de abril) e em dois no Público (em 2 e 3 de maio).

iii No caso brasileiro, uma determinação do Estatuto da Criança e do Adolescente (1990).

Este artigo e todo o conteúdo da Estudos em Jornalismo e Mídia estão disponíveis em http://www.periodicos.ufsc.br/index.php/jornalismo/index

Estudos em Jornalismo e Mídia está sob a Licença Creative Commons. 